DOI: $10.1590 / 2316-4018389$

\title{
A narrativa entre aspas de Bernardo Carvalho: legitimação e paratopia em um estudo de Onze: uma história
}

Paulo César Silva de Oliveira*

\section{Introdução}

Este artigo tem como objetivo estudar o primeiro romance de Bernardo Carvalho, Onze: uma história (1995), a partir de certos posicionamentos críticos da análise do discurso, especialmente os advindos da obra de Dominique Maingueneau. Destacaremos as questões de legitimação e paratopia do escritor para traçar um quadro introdutório da poética de Carvalho, que tem em Onze um ponto de partida singular. Situaremos o romance no quadro mais geral da literatura contemporânea, a saber, em meados da década de 1990, visando a estabelecer seu lugar no conjunto das produções hodiernas. Em seguida, discutiremos como as noções de paratopia, legitimação e autoridade formam um trio de questões críticas importantes para o que hoje, em 2011, já podemos chamar de obra, ao nos referirmos ao conjunto da ficção de Carvalho. Ao fim deste artigo, mostraremos de que forma o ficcionista elabora uma narrativa "entre aspas", termo tomado de empréstimo a Jacques Derrida (1990) e que será explicitado ao longo deste trabalho.

A obra de Bernardo Carvalho compõe-se, hoje, de um número já significativo de romances, sem contar suas incursões pelo conto, pela narrativa infantojuvenil, seu trabalho no terreno das crônicas e traduções, em blogs e mesmo nas artes visuais, para ficarmos em algumas de suas mais frequentes atividades. Não sendo o objetivo de nosso trabalho tratar de cada uma dessas atividades literárias em particular, queremos, no entanto, destacar o papel ativo do escritor na construção não somente de uma poética de romance, mas de uma trajetória multifacetada, que inclui ainda trabalhos com o teatro e páginas de crítica. Desde sua estreia no romance com Onze: uma história, Carvalho vem construindo uma obra de temas obsessivos na qual a trama discursiva nos revela uma vontade de desestabilizar certos parâmetros da narrativa tradicional por meio de estratagemas engenhosos, ainda que alguns excessos possam ser reconheci-

\footnotetext{
* Doutor em Ciência da Literatura pela Universidade Federal do Rio de Janeiro. Professor Adjunto de Teoria Literária da Universidade do Estado do Rio de Janeiro/Faculdade de Formação de Professores. E-mail: paulo.centrorio@uol.com.br.
} 
dos e questionados. O fato é que Carvalho vem criando espaços ficcionais os quais, conforme pretende o próprio escritor, chamaremos de mundo - e nele Carvalho se destaca no universo crítico da paratopia do autor, noção estabelecida por Dominique Maingueneau para designar "a difícil negociação entre o lugar e o não-lugar, uma localização parasitária que vive da própria possibilidade de se estabilizar" (Chareaudeu e Maingueneau, 2008, p. 368).

Para Maingueneau, a existência da paratopia está condicionada ao processo criador e o escritor constrói seu território em um entre-lugar dado: entre o espaço literário a que pertence e constrói e a sociedade na qual se insere. Mas não é a relação exclusiva entre o escritor e a sociedade que o torna paratópico e sim aquilo que Maingueneau chama de posição insustentável, paradoxal pela qual o escritor estabelece uma maneira singular de relacionamento com as condições de produção de sua obra em uma determinada época. Assim, a produtividade do conceito de paratopia nos leva a entender que o próprio processo da atividade de criação, por um lado, e as elaborações da enunciação, por outro, estão imbricados na dinâmica da constituição e produção de uma obra dada. Nesse processo criador, surgem as possibilidades de acesso a lugares interditados, somente possíveis no processo de elaboração da obra.

E de que forma se caracteriza a busca dos escritores por esse espaço incriado, em constante deslocamento, o qual visa mesmo a tornar-se lugar incomum no campo literário da narrativa contemporânea?

Poderíamos partir de uma definição do próprio Bernardo Carvalho, de que escreveria para criar um mundo onde pudesse caber. Essa afirmação, deslocada de seu contexto - o de uma entrevista ao jornal literário Rascunho - e recentemente publicada em livro (Pellanda, 2010), pode nos levar a uma ideia equivocada de resquícios românticos, de uma suposta nostalgia do gênio ou de um idealismo rondando a figura do autor. Portanto, é preciso contextualizar a frase no âmbito da pergunta feita pelo entrevistador, Rogério Pereira. Pereira quer saber de Carvalho o que lhe dá forças para enfrentar a ficção. A resposta de Carvalho é a seguinte:

O máximo que posso dizer para tentar responder à sua pergunta é um truísmo: que fico mal se não escrevo. E que me faz bem escrever. Ou que escrevo para criar um mundo em que a utilidade não seja uma exigência. Um mundo em que eu caiba. Mas, com isso, eu já estaria tentando atribuir uma função à literatura, e esvaziando o que há nela de mais libertário e surpreendente, que é não precisar de nenhuma razão. (id., p. 29)

Percebemos na "resposta" do escritor alguns elementos importantes 
de reflexão: o papel do autor; a definição do literário; a utilidade e o uso da literatura; a função da literatura; uma impossibilidade de definição do campo literário etc.

Aliam-se a esses elementos dois outros, também destacados na mesma resposta de Carvalho e que nos interessam neste trabalho. O primeiro, diz respeito ao que o ficcionista entende por "uso decorativo, social ou mercadológico" da literatura; e o segundo, ao esforço que a literatura demanda, por ser "uma experiência solitária" (id., ibid.). Para as reflexões que se seguirão nesta investigação, a tentativa de criação, de ficcionalização de um mundo à parte como uma forma de entrada no campo literário nos fornece uma chave para o que, na obra de Carvalho, se nutre de certos parâmetros, dentre os quais destacaremos o jogo narrativo compreendido como um conjunto de estratégias de encobrimentos; de crítica às convenções e aos estereótipos, à doxa; e de uma lógica que precisa ser desmascarada e desconstruída pelas políticas textuais. Não é um mundo tranquilo, estável, e por isso mesmo encontra-se sob condições, aspado. Como o próprio autor diz, há uma busca - obsessiva, acrescentaríamos - de uma lógica onde não há nenhuma lógica.

Esse artigo se dirige a esse universo difuso e elege o romance Onze como o objeto inicial de nossas preocupações. Algumas referências a obras posteriores, no entanto, por vezes serão necessárias.

\section{Onze e a narrativa contemporânea}

Primeiro romance de autor jovem, é natural que a recepção (boa) a Onze tenha gerado controvérsias no âmbito da crítica, especialmente na chamada crítica de rodapé. Conforme definiu Alfredo Bosi, as manifestações críticas "não chegam a constituir atualmente um debate literário minimamente coerente", pois "o consumismo pós-moderno é fundado no valor da mercadoria ao mesmo tempo nova (ainda que só aparentemente) e necessariamente descartável, pois a mola do sistema é a sua aparente capacidade de substituir o ontem pelo hoje, que amanhã já será ontem" (Bosi, 2001, p. 13).

No Editorial de Rodapé: crítica de literatura brasileira contemporânea (2001), do qual extraímos a afirmação de Bosi, a comissão executiva da publicação define a necessidade do periódico por conta das lacunas existentes entre a academia e a chamada "crítica de rodapé", lacunas essas que pretende preencher. Para os editores da Rodapé, "enquanto os jornais e revistas cuidam da carne fresca, o professor universitário trata de matéria sedimentada. Ele receia aproximar-se da produção de seu tempo porque, 
entre outras razões, não dispõe do necessário distanciamento histórico" (Bosi, 2001, p. 8). Daí essa divisão do trabalho resultar em uma "terceira margem" (termo cunhado pelos editores da publicação), papel a que se dedica o periódico em questão, o de tirar os escritores recentes do limbo, embora alguns até tenham sido contemplados com uma ou outra resenha midiática. Rodapé justificaria sua existência, portanto, pela contribuição produtiva na elaboração de uma consciência crítica acerca da literatura contemporânea. A discussão não é nova, é só recordar as observações de Machado de Assis acerca da construção de uma consciência crítica em seu tempo: "Não compreendo o crítico sem consciência. A ciência e a consciência, eis as duas condições principais para exercer a crítica" (Assis, 1986, p. 798).

Ocorre que, no caso de escritores que se iniciam na aventura das letras - como o então jovem autor de romances, Bernardo Carvalho, em 1995ํㅡ pode ser que sejam "velhos demais para a imprensa e novos demais para a academia" (Bosi, 2001, p. 9). A força de uma obra, isto é, o impacto e a permanência daquilo que elegemos como poética de autor, consistência artística, depende também, dentre outras questões, das lutas internas e dos mecanismos que regem o que Pierre Bourdieu vai chamar de "sistema de linhas de força", dentro do qual a criação artística se realiza:

Para dar à Sociologia da criação intelectual e artística seu objeto próprio e, ao mesmo tempo, seus limites, é preciso perceber e considerar que a relação que um criador mantém com sua obra e, por isso mesmo, a própria obra são afetadas pelo sistema de relações sociais nas quais se realiza a criação como ato de comunicação ou, mais precisamente, pela posição do criador na estrutura do campo intelectual (ela própria função, ao menos por um lado, de sua obra anterior e da aceitação obtida por ela). Irredutível a um simples agregado de agentes isolados, a um conjunto aditivo de elementos simplesmente justapostos, o campo intelectual, da mesma maneira que o campo magnético, constitui um sistema de linhas de força: isto é, os agentes ou sistemas de agentes que o compõem podem ser descritos como forças que se dispondo, opondo e compondo, conferem-lhe sua estrutura específica num dado momento do tempo (Bourdieu, 1967, p. 135).

\footnotetext{
${ }^{1}$ Vale lembrar que a primeira obra integral de Carvalho publicada em livro é a coletânea de contos Aberração, de 1993, reeditada em 2004 pela Companhia das Letras. As primeiras linhas que abrem o primeiro conto da obra antecipam uma característica relevante de sua ficção posterior: "Tudo que ae fez, disse ou sentiu na vida é falso. Tudo o que ae escreveu é mentira. Todas as cartas que me mandou” (Carvalho, 2004, p. 11).
} 
Como mostra Bourdieu, cada um dos sistemas se opõe ou se agrega em um tempo determinado, por meio de um tipo determinado de participação no campo cultural, possuindo peso funcional que varia de acordo com a posição do elemento no campo. Ao ressaltarmos a emergência da pós-modernidade, na fala de Bosi, o papel da crítica midiática e a atuação das academias - sem esquecer que os processos de legitimação constitutivos de um campo cultural dado dependem da atuação e peso funcional (Bourdieu) de cada elemento nesta relação sistêmica -, queremos compreender o surgimento de um autor jovem (com peso e função diferenciados no sistema de relações a que alude Bourdieu) no emaranhado contemporâneo de vozes ficcionais.

Prosseguindo, a criação de um lugar em que possa caber será circundada, na obra de Bernardo Carvalho, por um conjunto de escolhas autorais bem demarcadas. São caminhos e mesmo performances constitutivas da poética do jogo - jogo da ficção, das relações entre narração e história; entre real e imaginário. São jogos verbais e sintáticos, em suma, o que denominaremos poética do jogo. Assim é que, em nossa leitura do romance Onze, proporemos o termo teatro das aspas, por nós apropriado a partir da reflexão de Jacques Derrida ${ }^{2}$, a qual nos auxiliou sobremaneira em muito do que se dirá aqui.

Na obra de Bernardo Carvalho, uma insistente relação entre artifício e realidade é construída habilmente por meio de estratégias narrativas as quais, em maior ou menor grau e extensão, repetem-se obsessivamente no conjunto de romances do autor. Em Onze, a partir de um breve resumo para os que não estão familiarizados com o romance, partiremos da questão dos narradores para então nos estendermos acerca de outros elementos constitutivos da economia interna da narrativa.

\section{Paratopia, legitimação e autoridade}

Em um sítio no interior do Estado do Rio de Janeiro, encontramos um grupo de onze pessoas (o leitor verá que há ainda outros personagens,

\footnotetext{
${ }^{2} \mathrm{O}$ termo por nós apropriado encontra-se em um nosso artigo, intitulado "Derrida e Heidegger: estratégias da desconstrução” (Oliveira, 2009). Nela, discutíamos a questão levantada por Derrida (1990) acerca da palavra Geist, que aparece aspada na obra de Heidegger até o momento de sua suposta adesão (aqui não se discutirá o fato histórico, mas a alusão derridiana é necessária) ao nazismo, quando as aspas são retiradas e a palavra Geist se confunde com o “espírito alemão”. Derrida traça, na obra de Heidegger, o percurso do Geist, e mostra que aquilo que mais tarde surgirá em Heidegger como “o espírito alemão” já era um insistente consórcio entre seu pensamento e a ideologia que se tornará dominante. Com isso, Derrida mostra que toda obra, filosófica ou não, é aspada, marcada por esse movimento de velamento/desvelamento.
} 
presentes ou referidos) brincando do jogo de morto-vivo. Os dramas individuais se ligam especialmente, mas não exclusivamente, a seus relacionamentos. As vidas desses personagens estão em sincronia com uma série de eventos ligados a outras onze pessoas massacradas no aeroporto de Orly, em Paris. Entre os dois eventos (o do sítio e o do aeroporto de Orly), uma terceira seção trata do destino de um menino com uma doença rara, por conta da qual não consegue ver nos textos algumas vogais. Completa a estrutura do romance um apêndice o qual, saberemos, será referido ao longo da narrativa, composto pelo texto "Duas guerras", espécie de carta/relato de um pai ao filho desconhecido.

Uma breve análise dos paratextos do romance já nos é reveladora de certos pressupostos. $\mathrm{O}$ título do romance se refere a um grupo de pessoas, conforme já dissemos, em um sítio e ao mesmo tempo diz algo acerca do destino de onze indivíduos assassinados no hall do aeroporto de Orly. O sentido de grupo, de coletividade, dado pelo número onze, é repartido ao meio pelo advento dos dois pontos, como um muro dividindo espaços, mundos duplicados que, no entanto, estão em diálogo/sintonia, já que os dois pontos pressupõem um determinado olhar, uma brecha, uma vereda, conforme analogia possível com o paratexto de outro romance, nosso muitíssimo conhecido Grande sertão: veredas. Nele, também a oposição entre o "grande" e o "menor", ou seja, entre a amplitude do relato de grandes temas, da epopeia de um herói problemático contrasta com a observação miúda das vidas comezinhas, dos pequenos casos e dos longínquos lugares que, na arquitetura do romance de Guimarães Rosa, constituem a fabulação da obra.

Os onze do romance de Carvalho estão mirando o um, pressuposto no subtítulo "uma história", e vice-versa, como em um espelho, ou seja: dispersão e unidade, olhar múltiplo e uno, o título da obra invoca uma característica muito presente na poética de Carvalho e que vale para os processos globais de reflexão ficcional na contemporaneidade, formando uma espécie de anátema: impossibilidade da subjetividade na diluição da multidão, mas ao mesmo tempo retorno da ideia de uma indivisibilidade do sujeito individual que, no entanto, não pode mais ser reapropriado sob o crivo da ideia de identidade. Daí a existência em trânsito dos personagens de Carvalho, sempre à procura de algo ou em processo de fuga. São personagens indigitados (como o narrador de "Duas guerras"), que não conseguem se estabelecer no dito mundo real, sujeitos marcados por uma diferença que os coloca em um determinado fora em relação aos parâmetros da organização do corpo social, familiar, histórico. 
Esses processos de fuga, de recuperação do passado, de deslocamentos de perspectiva, necessariamente, implicam para o leitor buscar modos de acesso ao texto que nem sempre são imediatamente reconhecíveis. Se os temas de Onze são duros - a luta do sujeito subalterno pela afirmação ainda que impossível de sua identidade; a questão da doença (a AIDS paira sobre a narrativa como uma forma metafórica de maleita contemporânea); o terrorismo, o assassinato, tais temas entrelaçam as tramas que se desenrolam, aparentemente, de forma caótica e desconexa. As personagens, quase todas elas, são expostas à virulência de um mal-estar no mundo que é não somente de ordem psicológica, mas também política e ideológica. Daí nossa leitura da paratopia como uma chave de reflexão da condição não apenas do autor, mas da forma como ele se relaciona com sua obra, que é recebida pelo leitor como um conjunto de fatores em oposição e diálogo, inclusive reclamando a própria presença da autoria, na forma como reflete Maingueneau (2001, p. 45): “O importante é a maneira particular como o escritor se relaciona com as condições de exercício da literatura de sua época" (itálicos do autor). Ou seja, se no campo da economia das trocas simbólicas a posição do escritor é sempre problemática, visto que todo autor nega sua dependência em relação ao mercado, mas dele, paradoxalmente, obrigado a participar, seu estar no mundo é da ordem da crise. Como a literatura é uma instituição, e toda instituição cria suas instâncias de legitimação, o escritor negocia com esses campos de força de forma ao mesmo tempo particular, individual e autônoma, por um lado e, por outro, expondo-se aos imperativos do mercado simbólico.

A legitimação como parte do processo de inserção do autor e de sua obra no mundo encontra o sujeito criador em uma determinada situação particular ou social, como é o exemplo dado por Maingueneau, no caso das uniões civis, do estado de direito democrático, da filiação etc. Precisamos, portanto, estender a reflexão inicial da situação paratópica do escritor aos problemas oriundos dos processos de legitimação.

A noção de legitimação em análise do discurso "pode ser utilizada para significar que o sujeito falante entra em um processo de discurso, que deve conduzir a que reconheça que tem direito à palavra e legitimidade para dizer o que diz" (Charaudeau e Maingueneau, 2008, p. 295) e essa situação deriva tanto de uma situação factual, na qual todo interlocutor em presença advoga para si o direito de falar, quanto da posição que ele ocupa em uma determinada instituição, adiantam Charaudeau e Maingueneau. Entretanto, como no caso dos escritores, há também a necessidade de se estabelecerem critérios de legitimidade, de acordo com a posição de autoridade do sujeito que toma a palavra: autoridade do saber 
(como no caso dos especialistas, da crítica, da erudição) ou autoridade pessoal, em que predominam os processos de sedução e persuasão.

Segundo Charaudeau e Maingueneau (2008, p. 93-4), a noção de legitimidade deve ser associada a duas outras: as de captação e credibilidade. Nas estratégias de captação, há persuasão e sedução, em que se procura partilhar a intencionalidade, valores e emoções de que o ato de comunicação é portador por meio da polêmica ou dramatização. Recordemos que, segundo Maingueneau, embora a história literária estabeleça dois pontos de oscilação com respeito à condição do escritor - de um lado, ele é um marginal e, de outro, alguém que precisa valer-se de seus direitos para sobreviver - a necessidade de institucionalização da literatura em si já cria o ambiente para que a situação paratópica do autor se desenvolva: os prêmios, as academias, os clubes, o reconhecimento da crítica, a figuração em antologias e livros escolares, por um lado, fazem o trabalho de inserção do autor no campo intelectual legitimador; por outro, aqueles que escapam às estratégias de institucionalização, como no caso dos escritores marginais, serão os elementos que mais fortemente legitimarão o campo literário, conferindo a este certo estatuto de independência, paradoxalmente formando no campo literário toda uma concepção de independência e liberdade criativas (Maingueneau, 2001).

As relações estabelecidas dentro do campo conceitual da "captação" não podem ser dissociadas dos efeitos subversivos que provocam, especialmente no que toca à questão do texto compreendido como "reinvestimento". Para Charaudeau e Maingueneau (2008, p. 94), se "a captação consiste em transferir para o discurso reinvestidor a autoridade relacionada ao texto ou ao gênero fonte", na subversão, ao contrário, "a imitação permite desqualificar a autoridade do texto ou do gênero fonte", como no caso da depreciação paródica. Neste sentido, será questionável a recusa hodierna a uma determinada filiação, atitude muito comum nas falas de escritores contemporâneos quando advogam para si uma singularidade questionável. Esta atitude pode revelar uma espécie de arrogância intelectual contemporânea, ou mesmo sublinhar um romantismo anacrônico em que se percebe uma exacerbação deslocada da subjetividade autoral, claro que considerando as singularidades de cada autor.

Lemos frequentemente, em várias declarações de autores - incluindo aí algumas entrevistas de Bernardo Carvalho -, que sua literatura não (se) reconhece (em) heranças, filiações e que ela nem mesmo se insere em qualquer grupo, categoria ou tribo, conforme o conceito especificado por Maingueneau (2001, p. 29-31), como se literatura não fosse ela própria já predeterminada por instâncias alheias à vontade de seus autores. Outra 
questão, mais relacionada à análise interna dos textos, diz respeito aos processos de leitura e interpretação, já que o destinatário sempre perceberá um discurso-fonte na leitura de textos quaisquer, ainda que esta leitura seja ambígua.

O que mais nos chama a atenção é o fato de que a produção contemporânea não corresponde à própria imagem que grande parte dos escritores cria para si no campo intelectual. Lembremos que a recepção das obras também faz parte dos componentes estruturais do campo intelectual e determinam relações, inclusive de poder e legitimação. A defesa de uma poética, válida e essencial a autores em sua relação com as obras que criam, não determina, obviamente, a forma com que serão lidos e recebidos seus textos, mas pode determinar (e, por vezes, orientar os leitores) sua posição no campo. Também as supostas independência e singularidade estão relacionadas aos próprios mecanismos de circulação, produção e legitimação de suas obras no mercado contemporâneo dos bens simbólicos, o que demonstra ser a apologia da autenticidade algo sempre problemático. Isso é especialmente embaraçoso para um conjunto de escritores que a todo o momento estão (legitimamente, diremos) negociando com as instâncias midiáticas, de legitimação, captação e credibilidade. É o caso, por exemplo, da relação cada vez mais acentuada de alguns escritores com a televisão, com o cinema, o teatro, dentre outros meios de divulgação e circulação da obra, relações legítimas, reafirmemos, mas que denotam posições assumidas no campo intelectual. Questionar o papel dos autores e obras no mundo atual requer reflexões pontuais, específicas no que se refere ao problema dos diversos contextos da obra literária no qual se destaca a função paratópica do autor.

Retomando nossas indagações acerca da legitimação, veremos que Maingueneau trata da "conivência" entre produtor e destinatário como fenômeno atravessado pela polifonia do texto: reconhecendo o valor do texto reinvestidor e do texto reinvestido, o destinatário percebe que há um processo de escolha em que um hipertexto determinado trava relações dialógicas com um hipotexto, seja ele explicitado ou não. Isso quer dizer que todo escritor mantém uma relação de dívida para com o texto parodiado, e essa relação é sempre ambígua. Daí subversão e reinvestimento serem elementos fundamentais no estudo das relações interdiscursivas que permeiam o discurso.

Um parêntese necessário, antes de prosseguirmos, trata da questão do destinatário (podemos chamá-lo simplesmente de o leitor) de uma obra literária, em nosso caso, a obra de Carvalho. Essa questão é crucial para a compreensão dos processos narrativos que se desenvolvem no multi- 
facetado campo intelectual das literaturas latino-americanas, das quais a brasileira é parte expressiva. Chamaremos ao debate a reflexão de Luiz Costa Lima quando, ao analisar outra obra de Carvalho, Teatro (1998), nos diz que neste romance:

Cria-se assim um fascinante quadro de incertezas que aposta em um leitor dotado de um interesse decifrativo semelhante. Ao mesmo tempo, porém, o autor tem a esperteza de não esperar necessariamente por este leitor. A trama é tão bem concatenada que o leitor pode simplesmente deixar-se conduzir pelas peripécias da intriga (É verdade que, com isso, não tirará do romance mais do que um entretenimento). Para o leitor mais exigente consigo mesmo algo distinto surgirá: uma inverossimilhança tornada verossímil, uma sóbria ambiguidade que sabiamente se oculta para quem não se disponha a indagá-la, eis o modo como o autor procura responder à situação contemporânea da prosa ficcional. Confiando a este leitor sensível e autoexigente as ambiguidades que constrói, resiste Bernardo Carvalho à literatura que procura conquistar o leitor pela acessibilidade; admitindo, pois, o caminho pelo qual opta a maioria, o autor não se exclui do acesso ao grande número. (Lima, 2002, p. 273-4)

Para confirmar sua leitura, Costa Lima aponta algumas estratégias de Carvalho: a utilização do romance policial, por um lado, identifica a maioria de seus leitores com um discurso literário tido como comercial; e, por outro, quando explora a relação entre normalidade e loucura confere à sua obra um teor de excepcionalidade e de pouca acessibilidade, em que o caráter hermético faz com que o leitor mais exigente se sinta desafiado e contemplado por seu esforço de decifração. Segundo Costa Lima, essa relação implica uma dupla decisão do autor, a de não perder de vista seu leitor e ao mesmo tempo revelar seu texto como "doença da linguagem" (id., p. 275), impedindo que o leitor receba o romance como mero divertimento.

Se os conceitos de reinvestimento e subversão introduzidos por Charaudeau e Maingueneau nos propiciaram pensar as relações de conivência autor-leitor, a leitura de Costa Lima vai nos mostrar que as estratégias de autor na relação com o leitor estabelecem sua posição no campo intelectual, reforçando a ideia de uma vontade de legitimação no campo intelectual de que participa. A análise de Teatro, portanto, servirianos para compreender o que em Onze: uma história também se anuncia como uma interpretação válida, tanto no que toca às questões de reinvestimento e subversão quanto ao posicionamento ambíguo do autor em face de seu potencial leitor.

142 estudos de literatura brasileira contemporânea, n.38, jul./dez. 2011, p. 133-152 
Também em Onze o jogo de espelhos faz com que a participação ativa do leitor se dê de forma a completar os reclames da máquina preguiçosa a que se referia Umberto Eco: o texto. Em Onze, o trabalho do leitor jamais é facilitado, mas, como em Teatro, a recorrência a técnicas narrativas do romance policial, da trama de suspense, das peripécias que se multiplicam na narrativa, faz com que o leitor, ao mesmo tempo, frua o texto sem perder de vista - caso seja o leitor-modelo de que o texto prescinde - que a realidade ali exposta é problemática e o texto está a todo o momento buscando desvendá-la ao mesmo tempo em que se desvenda para o leitor.

Fechado o parêntese, precisamos retomar o terceiro elemento na reflexão de Charaudeau e Maingueneau sobre a questão da legitimidade. A noção de credibilidade, bem resumida, "define o caráter de veracidade dos propósitos de uma pessoa (...) ou de uma situação", sendo "um julgamento feito por alguém sobre o que vê ou ouve e, por consequência, sobre a pessoa que fala, que é, desse modo, julgada 'confiável'" (Charaudeau e Maingueneau, 2008, p. 143). Como o sujeito precisa construir um discurso "confiável", devemos mais propriamente falar em "construção de credibilidade", propõem os autores; isso nos leva a considerar a credibilidade como um estado ou processo, ou seja, seria mais adequado falar em "credibilização". Ser levado a sério parece ser a condição da credibilidade, mas o que seria ser levado a sério no jogo ficcional? Como o escritor pode, ao mesmo tempo, instituir-se como autoridade "séria" se seu discurso participa, ao mesmo tempo, da ordem do fingimento? No caso de Bernardo Carvalho, o falso "se instala na própria realidade, tornando problemático o referencial", conforme Lima (2002, p. 275). O problema da credibilização, quando levado à reflexão da questão da autoria e da obra ficcional se mostra deveras produtivo, porém bastante discutível.

No processo de construção da credibilidade, o sujeito pode recorrer a três tipos de posicionamento: o de neutralidade, em que apaga traços de julgamento em seu discurso; de engajamento, quando o enunciador estabelece tomadas de posição; e de distanciamento, como no caso dos especialistas, em que se pressupõe uma atitude fria em relação ao objeto estudado. No processo da enunciação, neutralidade, engajamento e distanciamento são noções problemáticas, na medida em que se pode conceber, como no caso da fala (que é do que tratam Charaudeau e Maingueneau), certa permeabilidade entre os critérios de neutralidade, distanciamento e engajamento que, ao final, remetem-nos também à indecidibilidade.

Por isso Costa Lima é feliz ao mostrar que a forma como o escritor responde na contemporaneidade à situação da prosa requer uma crítica renovada ou, como chama, "um outro tipo de crítica literária", que fuja 
da resenha e da sedimentação acadêmica. Pensar e errar seriam sinônimos e/ou parceiros, o que leva Costa Lima a ver como falha de autor o fato de o leitor não encontrar brechas para completar o texto. A ideia de texto como obra aberta, como algo que nos entrega lacunas a serem preenchidas, a requerer um papel ativo do leitor, está sempre sendo retomada de uma forma ou de outra pela crítica, visto que essa abertura é marca do ficcional, de um modo geral, mas também expressa algumas formas obsessivas da pesquisa narrativa de hoje, em particular. Além disso, ao problematizarmos a fala de Costa Lima, veremos que o fato de Carvalho não deixar brechas ao leitor está de acordo com sua ideia da necessidade de criação, de se estabelecer um mundo onde o escritor possa caber. A paratopia do escritor aqui é uma noção especialmente importante. Por não permitir que o leitor complete a contento seu texto, Carvalho pode estar paradoxalmente apontando uma forma de ler, uma espécie de lance de dados do escritor que, inclusive, se imiscui na estruturação da obra e nela estabelece as bases de sua poética. A possibilidade de errar, como se vê, também nos faz recorrer à possibilidade de interpretar desarmados, como em um salto sem redes.

\section{A narrativa entre aspas: uma leitura de Onze}

Em nossa leitura de Onze: uma história, a relação entre autor e obra confirma uma expressão bastante feliz de Maingueneau, de que o escritor é filho de seu filho.

os membros das tribos literárias são extraídos de famílias, as quais, aliás, eles continuam a pertencer; por outro lado, por mais que a tribo não seja uma família, a intensidade das transferências afetivas que nela se produzem lhe faz manter relações não passíveis de decisão com a estrutura familiar. (Maingueneau, 2001, p. 30)

Ainda que reneguem o tribalismo literário, Maingueneau nos mostra que os escritores, quando pensam depender apenas de si mesmos, jamais conseguem sair do campo literário, "a partir do momento que escrevem, publicam e organizam sua identidade em torno dessa atividade". Os escritores dizem, conforme Maingueneau (id., p. 31), "cada qual à sua maneira, o que a literatura legítima é para eles. Daí que, ao invés de falha, como prevê Costa Lima, em relação ao romance Teatro, preferimos ver uma representação ficcional do papel da literatura para seu autor e uma proposta de poética em curso. Em Onze, esse jogo iniciático, por ser este o primeiro romance de uma obra que obsessivamente visa a questionar os limites entre real e ficcional demandará, por meio das escolhas de Car- 
valho, a inserção da questão autobiográfica nos modos de jogar, o que o texto reafirma.

$\mathrm{Na}$ "Parte dois" do romance, o primeiro capítulo se abre com a seguinte oração: "Quando acordei, meu pai se chamava Fábio, minha mãe Beatriz, meu nome Bernardo, e já era tarde" (Carvalho, 1995, p. 57). O fato de Carvalho imprimir seu nome a um personagem que destoa de sua posição paratópica do escritor e de seu mundo, faz com que possamos interpretar a questão do jogo entre biografia, autobiografia e ficção como elemento deveras importante de sua prosa. Isso irá repetir-se em outros romances de Carvalho, por vezes de forma invertida. Nas obras mais recentes, o próprio universo mundano do autor e seus pronunciamentos públicos acerca de sua poética podem ser analisados como matéria ficcional a confundir-se, por vezes, com a sua posição paratópica no mundo literário. $\mathrm{O}$ ato de escrever se encaminha cada vez mais para essa relação vida/obra - a bio/grafia, como propõe Maingueneau (2001) - na forma de uma atividade inerente à existência do escritor e, não mais, conforme apontamos em Onze, como jogo que visa a subverter, nos moldes da captação subversiva, as noções de autoria. O reinvestimento de Carvalho se dá não em relação a um autor específico com que dialogaria intertextualmente, mas em torno de um conjunto de escritores e de saberes a circundar o universo da relação autor/obra, em que percebemos estratégias e mecanismos de disfarce da vida na obra e vice-versa. Para ficarmos em alguns exemplos, neste sentido há, obviamente, uma filiação, explícita ou não, a vários escritores e escritos contemporâneos. Dentre eles, destacamos Cólm Tóibin, David Leavitt, Bruce Chatwin, dentre outros, autores em que não só a pesquisa acerca da autoria evoca a ficcionalização de escritores do passado, mas também o mundo do escritor e do próprio escritor compreendido como elemento ativo do texto ficcional (como no caso de David Leavitt, especialmente na novela "The term paper artist", da obra Akansas).

Talvez a afirmação de Maingueneau (2001, p. 56), de que não existe "gesto bio/gráfico cujo significado seja independente das reivindicações estéticas que fundamentam uma obra", pode ser muito discutida e mesmo combatida caso seja lida fora do contexto de sua análise da paratopia em Baudelaire. Sua posição é a de que o contexto não é um "fora", a dialogar com um "dentro", nem o "dentro" só pode significar a partir da naturalização do "fora". O escritor, por exemplo, também é criado pelo mundo que cria, ou seja: da mesma forma que a obra trata de seu contexto, ela própria é constituída pelo que visa a constituir. O mesmo ocorre com o autor. Assim, não há para Maingueneau oposição hierárquica entre obra e escritor, entre dentro e fora, mas trânsito. A noção de trânsito é impor- 
tante se estendida ao conjunto de romances que até agora formam o que chamamos de "a poética de Bernardo Carvalho".

Na narrativa de Onze, o mundo representado e o mundo de seu autor; o dado interno e as relações extratextuais são representados como suplementares e não se resolvem nas oposições dentro/fora, texto/contexto, forma/fundo. Uma passagem de Onze é emblemática, a esse respeito. A citação é longa, porém necessária:

Kill desenhava notas aparentemente idênticas às que existiam em todos os países por onde passava. Mas eram apenas semelhantes. Seu projeto era morar alguns meses em diferentes países e espalhar no mercado notas desenhadas à mão (por isso, dizia que era arte; tinha uma perspectiva quase renascentista, artesanal), cópias muito parecidas do dinheiro local. A certa altura, ele próprio informava às autoridades, aos jornais, à mídia o que tinha feito. Na verdade, as notas circulavam mais por distração de comerciantes e consumidores. O pânico no mercado fazia parte de seu trabalho também. Ia parar na justiça, como falsário, e seus argumentos também faziam parte do trabalho - os processos eram gravados e exibidos em seguida em museus, ao lado das notas. Era como se o mundo que o envolvesse - ou por onde passassem as notas - fizesse parte do trabalho. No início nenhum de nós percebeu a importância desse projeto, que achávamos apenas subversivo e perturbador de um mercado já quase morto. Mas o que eu já não sei mais depois desse artigo que descreve o processo final - que nada tem a ver os anteriores - em consequência da passagem de Kill pelo Brasil. (Carvalho, 1995, p. 85)

Esse trabalho de interferência da arte no real será alvo de um desafio, proposto por um estudante de história da arte: de que o projeto do artista não teria sentido "no país do dinheiro", no caso, o Brasil. O objetivo do estudante era o de usar a experiência radical de Kill no Brasil como parte de sua tese de doutorado. Se Kill mostrava o poder de interferência da arte no real por meio de sua provocação com as notas falsas pintadas à mão e espalhadas pelos mercados nos países onde atuava, o rapaz pretendia provar a prevalência da realidade sobre a arte, que a obra não era universal e seus efeitos não se dariam uniformemente. Carvalho tematiza as aporias da arte contemporânea e sua obsessiva verve desmistificadora do real que, para o estudante de arte na passagem referida, significava um retorno do pintor a uma espécie de romantismo enganoso. Mas as interpretações do narrador no capítulo em questão nos mostram que, na 
verdade, outras possibilidades interpretativas caberiam na aposta feita pelo estudante, que poderia estar defendendo a beleza da arte justamente localizada nessa impossibilidade do autor de vencer a realidade:

A própria tese do rapaz, cujo resumo é descrito no artigo, parece levar à conclusão de que é por não ser onipotente que o trabalho de Kill é fenomenal, é justamente por não poder vencer a realidade que a arte de verdade a desafia, que a beleza desse romantismo está no fracasso. Ou talvez seja apenas eu. (id., p. 86)

Os estatutos das relações entre arte e realidade são postos, dessa maneira, em perspectiva, estabelecendo possibilidades renovadas de compreensão crítica dos espaços de legitimação. A questão da arte como cópia, como performance, espetáculo, retoma antigas questões acerca da função do objeto estético e de sua natureza. Teria a arte contemporânea esse papel de retomar certo caráter de intervenção da arte nos processos de compreensão e organização do real? Seria a arte aquela espécie de língua fora do poder, ou aquilo que na porosidade das estratégias de autoridade e legitimação poderia sobreviver aos mecanismos de repressão do poder, como um organismo parasitário, como as notas falsas de Kill, ao mesmo tempo participando do sistema e corroendo-o, pelas brechas? As duas possibilidades formam dois modos de compreensão e discussão teórica da matéria ficcional de Onze. Essa estrutura dialógica, que permeia uma crítica por vezes virulenta, outras vezes irônica das concepções românticas de mundo desconstruídas no romance é estruturada por meio de um contrato realista com o mundo, em que percebemos algumas questões mais urgentes e objetivas - a AIDS, o terror, a arte contemporânea, a injustiça social, a perversão dos processos de globalização, exploração do capital, crime etc. Por outro lado, vemos que a narrativa de Carvalho desautoriza essa aparente adesão aos princípios do contrato realista ao desnudar-se a todo o momento como farsa, construção discursiva do inverossímil tornado verossímil. Daí que o romance assume um tom descritivo nas ações e o mescla a uma espécie de ensaio ficcional, pelo qual os narradores refletem a realidade, a tematizam e criticam, teorizando-a. Esse hibridismo da escrita é também mais uma das facetas do jogo de espelhos da poética do autor: nem ficção realista, nem ensaio; nem verossímil, nem inverossímil, mas uma narrativa que dialoga, sem optar por um ou por outro, com os entre-lugares da ficção e da reflexão.

Em Onze, os poderes da arte esbarram nos poderes da realidade. Mercadoria, exploração, capital, ideologia são associados a dois tipos de representação do artista: um, que desafia os sistemas financeiros dos países onde a moeda representa a estabilidade financeira das economias domi- 
nantes, mas que fracassa no "país do dinheiro", em que a corrosão da moeda é mais virulenta do que sua possibilidade de permanência nos mercados; e outro, que se vale da miséria de meninos pobres da periferia para "criar" suas obras, e que na verdade estaria por detrás do comércio de órgãos humanos. Para o primeiro modelo de artista, a segurança de expor sua tese em países estáveis financeiramente contrasta com a dificuldade de defender um conceito estranho a uma cultura da volatilidade da moeda, no caso, o Brasil inflacionário do período pós-ditatorial. Já o segundo tipo de artista é construído pelo olhar do narrador-adolescente, de nome Bernardo - o qual nutre sentimento de revolta por conta da vida que lhe foi destinada; e que por isso atira o irmão do apartamento "porque já tinha gente demais no apartamento de quarenta metros quadrados quando ele nasceu" (id., p. 57). Por conta dessa revolta, decide matar o pintor que o explora, embora para o leitor pairem dúvidas sobre a veracidade dos fatos, a partir do momento em que também há dúvidas sobre o que é narrado. Exemplifiquemos.

À narrativa supostamente realista, Carvalho sobrepõe outra, a qual insinua que a imaginação moldava a percepção do menino, o que para o pintor, deveria ser canalizado para a pintura: “(...) e disse que era só a minha imaginação e que se eu tinha uma imaginação tão fértil devia pintar sobre tudo o que via, que não era a realidade" (id., p. 77). Ademais, esse narrador também não consegue "ler" competentemente, por conta de uma estranha disfunção, que lhe impede de ver as vogais a, o, e. Problematizando as relações arte/engajamento, arte/sociedade, arte/autoria, leitor/leitura, real/imaginado, Onze insere no campo de questionamentos o próprio leitor, conclamado a fazer funcionar a máquina preguiçosa do texto, enquanto esse mesmo texto se desmente como possibilidade de leitura unívoca.

Para os dois artistas representados nos dois capítulos simétricos da segunda parte do romance, também a realidade passa a conviver com o mundo que criam e não apenas como representação, já que os efeitos de sua obra na realidade também se tornam eles próprios matéria da criação, pressupostos pela própria obra que interfere no cotidiano. Por isso, também as ações judiciais contra a distribuição de notas falsas no mercado passam a fazer parte dos processos de criação, circulação e inserção da obra no mercado, como mercadoria - réplica do dinheiro - e objeto cujo valor transcende o da própria mercadoria. Tudo sob a forma de exposição midiática. A realidade será, portanto, naturalizada, por um lado, e mais tarde exposta no espaço maior da sacralização, o museu. Isso nos leva a compreender o que Maingueneau nos mostrara como relação indissociável entre texto e contexto. 
No caso do Brasil, a inflação galopante do período retratado faz com que as notas não possam ser inseridas no mercado, pois, ao perder seu valor quase que instantaneamente, seu valor artístico como objeto provocador não surtirá o efeito pretendido. A arte requer um tempo determinado e a relação problemática com o tempo da realidade que daí decorre passa a corroer também os efeitos pressupostos pelo objeto artístico.

Nem visão romântica da arte, nem narrativa realista. O fracasso do artista e de sua obra, no Brasil, recupera as noções de paratopia do artista, além de questionar os conceitos de verossimilhança (as notas têm que ser perfeitas para que possam circular) no choque com a realidade em culturas diferenciadas. Onze é, nessa perspectiva, uma análise dos poderes da arte frente ao real em que se discute a posição do artista na sociedade contemporânea, o poder do discurso e da literatura em uma realidade que os destitui deste mesmo poder, seja por meio da suspensão na crença nos poderes do autor; seja, na forma da narrativa, por meio da dispersão do relato em vários narradores os quais não organizam, ao final da trama, uma unidade discursiva tal que nos permita "interpretar" a história que se conta. Assim, as três partes do romance mais o apêndice, bem como os capítulos que compõem cada uma das partes, se atraem e repelem, requerendo novos modos e possibilidades de leitura, o que reafirma a necessidade apontada por Costa Lima de uma crítica renovada, que dê conta desses novos reclames e se arrisque ao erro: o real representado em Onze é da ordem da dispersão. Não há possibilidade de o leitor organizar adequadamente as ações e eventos descritos. Algo sempre se perderá neste tipo de obra, e a possibilidade de a leitura revelar algo também faz parte do processo esquizofrênico de ordenar o que o real instaura.

\section{Reticências e ponto final}

Vamos nos valer de uma citação de um livro pequeno e notável de Costa Lima, escrito em 1966: "Igualmente, quando nos perguntamos por que a literatura, estamos a indagar por qual o sentido da sua expressão para o homem contemporâneo" (Lima, 1966, p. 15). A citação, pertinente à época, vale muito hoje, pelo caráter de permanência que sua reflexão carrega.

A narrativa de Carvalho, especialmente em nosso objeto de análise, Onze: uma história, reclama uma leitura entre aspas. Porque é uma narrativa aspada em que a retirada das aspas implica novamente a recolocação das mesmas. Ao dissociarmos o real do imaginado, vemos que os processos imaginativos passam a ser eles próprios uma espécie de real, invertido 
ou duplicado. Um e outro participam de um jogo em que "vida e ficção se mostram confundidas", não como apêndice do enredo, mas "parte essencial da estrutura" (Lima, 2002, p. 281). O real passa a existir no texto, conforme Costa Lima, como processo mistificador. Não demite, entretanto, a denúncia de um mundo em que a arte é também homóloga a uma representação da barbárie que perverte e corrói as estruturas sociais que denuncia, ao mesmo tempo em que denuncia a si própria como elemento ratificador de uma cultura do horror a qual representa.

Nosso breve ensaio propõe mais do que resolve. Ao compreender a paratopia do escritor sob o crivo de uma escrita que torna autor, autoria e texto instâncias problemáticas e que envolvem o leitor nos processos que subverte - ele próprio o leitor, subvertido nestes processos - elegemos a crítica e a Teoria Literária como entidades provocadas a refletir sobre os fenômenos literários hodiernos. Ambas se fazem necessárias quando percebemos a precariedade e transitoriedade de nossas "respostas".

Deste modo, a uma literatura entre aspas será preciso compreender a crítica ela própria como atividade aspada. Mas não será esse o crivo por que passa todo o discurso literário dito autêntico, ainda que nos arrisquemos a encerrar este artigo com uma categoria tão romântica como a autenticidade? Aspemos a noção. Aspemos nosso discurso.

\section{Referências bibliográficas}

ASSIS, Joaquim Maria Machado de (1986). Obra completa. Rio de Janeiro: Nova Aguillar. v. 3, p. 798-801.

BOSI, Alfredo (2001). "Entrevista". In: Rodapé: crítica de literatura brasileira contemporânea. São Paulo: Nankin Editorial. p. 13-7.

BOURDIEU, Pierre (1967). "Campo intelectual y proyecto creador". In: POUILLON, Jean (Org.). Problemas del estructuralismo. México: Siglo Veintiuno Editores.

CARVALHO, Bernardo (1995). Onze: uma história. São Paulo: Companhia das Letras.

(1998). Teatro. São Paulo: Companhia das Letras.

(2004). Aberração. São Paulo: Companhia das Letras.

(2010). “O agente da solidão”. In: PELLANDA, Luís Henrique (Org.) As melhores entrevistas do rascunho. Porto Alegre: Arquipélago Editorial. v. 1. CHAREAUDEU, Patrick e MAINGUENEAU, Dominique (2008). Dicionário de análise do discurso. 2. ed. São Paulo: Contexto.

DERRIDA, Jacques (1990). Do espírito. Campinas: Papirus.

GENETTE, Gérard (1982). Palimpsestes: la littérature au second degré. Paris: Seuls. 
ISER, Wolfgang (1980). The act of reading: a theory of aesthetic response. Baltimore: London: The John Hopkins University Press.

LIMA, Luiz Costa (1966). Por que literatura. Petrópolis: Vozes. p. 15. (2002). Intervenções. São Paulo: Edusp.

MANGUENEAU, Dominique (2001). O contexto da obra literária. São Paulo: Martins Fontes.

OLIVEIRA, Paulo César Silva de (2010a). Poética da distensão (entre a transcrição da paisagem e a escritura do caminho: crítica e desconstrução no Grande sertão: veredas). Manaus: Edições Muiraquitã.

(2010b). "No aqui e agora da ficção brasileira: uma leitura de O filho da mãe, de Bernardo Carvalho". Revista Uniabeu. Rio de Janeiro. v. 3, p. 57-69. Disponível em: <http:/ / www.uniabeu.edu.br>.

(2009). "Derrida e Heidegger: estratégias da desconstrução". Revista Eletrônica Cadernos da FaEL. Disponível em: www.unig.br/cadernosdafael. v. 2, n. 5, mai.-ago.

(2007). "Que narrativa, que história? Sobre a errância na prosa de Bernardo Carvalho". In: Anais do XI Encontro Regional da Abralic. São Paulo: USP/Abralic. p. 1-10.

(2004). “História em ruínas no jogo ficcional: a escritura radical de Bernardo Carvalho". In: Anais do IX Congresso Internacional Abralic. Porto Alegre: UFRGS/Abralic. v. 1, p. 1-8.

(1999). "Literatura e pensamento: Heidegger e Derrida em questão". In: Fronteiras da literatura: discursos transculturais. Rio de Janeiro: RelumeDumará. v. 2, p. 19-23.

PELLANDA, Luís Henrique (Org.) (2010). As melhores entrevistas do rascunho. Porto Alegre: Arquipélago Editorial. v. 1.

SCHOLLHAMMER, Karl Erik (2009). Fiç̧ão brasileira contemporânea. Rio de Janeiro: Civilização Brasileira.

SPIVAK, Gayatri Chakravorty (2010). Pode o subalterno falar? Belo Horizonte: Editora UFMG.

Recebido em maio de 2011.

Aprovado em julho de 2011.

\section{resumolabstract}

A narrativa entre aspas de Bernardo Carvalho: legitimação e paratopia em um estudo de Onze: uma história

Paulo César Silva de Oliveira

A situação paratópica do escritor latino-americano e a questão da legitimação são os pontos de partida desta reflexão, concentrada na análise do romance Onze: uma história, de Bernardo Carvalho. As relações entre local e global; entre as políticas 
de autor e políticas do texto, bem como o lugar da ficção brasileira no contexto das narrativas contemporâneas serão investigados na máquina textual de Carvalho visando a uma reflexão acerca dos alcances e limites de sua escrita em face de uma modernidade constituída por deslocamentos, cruzamentos e diluição das fronteiras políticas, geográficas e narrativas.

Palavras-chave: literatura, contemporaneidade, teoria

The story quoted by Bernardo Carvalho: legitimation and paratopia in a study of Onze: uma história

Paulo César Silva de Oliveira

The paratopic situation of the Latin American writer and the legitimating process are the starting point of this article, concentrated on the analysis of the novel Onze: uma história, by Bernardo Carvalho. The connections between local and global; author policies and text policies; as well as the place held by the Brazilian fiction in the contemporary scenario will be investigated inside Bernardo Carvalho's textual machine, aiming at establishing limits and reaches of his writings regarding a modernity constituted by displacements, border crossings, and the dilution of political, geographical and fictional frontiers.

Key words: literature, contemporary, theory

Paulo César Silva de Oliveira - “A narrativa entre aspas de Bernardo de Carvalho: legitimação e paratopia em um estudo de Onze: uma história". Estudos de Literatura Brasileira Contemporânea, n. 38. Brasília, julho-dezembro de 2011, p. 133-152. 